\title{
Calmodulin-Binding Protein Detection Using a Non-Radiolabeled Calmodulin Fusion Protein
}

BioTechniques 30:1036-1042 (May 2001)

\author{
Gloria Murray, Mathew J. \\ Marshall, William Trumble, \\ and Bernadene A. Magnuson ${ }^{1}$ \\ University of Idaho, Moscow, \\ ID, and ${ }^{1}$ University of Mary- \\ land, College Park, MD, USA
}

\begin{abstract}
Calmodulin-binding proteins are involved in numerous cellular signaling pathways. The biotinylated-calmodulin overlay is a nonradioactive method widely used to detect calmodulin-binding proteins in tissue and cell samples. This method has several limitations; therefore, we developed a nonradioactive calmodulin-binding protein detection overlay using an S-tag ${ }^{\mathrm{TM}}-l a b e l e d$ calmodulin fusion protein. An expression system was used to generate a calmodulin fusion protein with an S-tag label, a 15 amino acid sequence that binds to a 105 amino acid S-protein ${ }^{\mathrm{TM}}$. The S-protein is conjugated to horseradish peroxidase for final detection with a chemiluminescent substrate. The S-tag calmodulin was compared to purified calmodulin and biotinylated calmodulin in a calmodulin-dependent phosphodiesterase assay. The results of the calmodulin-dependent phosphodiesterase assay indicate that $S$-tag calmodulin induces higher phosphodiesterase activity than biotinylated calmodulin and lower activity than purified calmodulin. A comparison of the biotinylated and S-tag calmodulin overlay assays indicate that $S$-tag calmodulin is more sensitive than biotinylated calmodulin in the detection of calcineurin, a known calmodulin-binding protein. The overlay assay results also indicate that the $S$-tag calmodulin and biotinylated calmodulin detect similar calmodulin-binding proteins in colon epithelial cells. In conclusion, the $S$ tag calmodulin overlay assay is a consistent, sensitive, and rapid nonradioactive method to detect calmodulin-binding proteins.
\end{abstract}

\section{INTRODUCTION}

Calmodulin, a calcium-binding protein of approximately $17 \mathrm{kDa}$, plays multiple roles in cellular calcium regulation (8). The binding of calcium to calmodulin enables it to regulate the activity of many calmodulin-binding proteins such as kinases, phosphatases, ion transporters, nucleic acid regulating proteins, and cytoskeletal proteins within the cell $(6,16)$. To identify calmodulin-binding proteins in small samples of cellular extracts and tissue homogenates, several overlay methods using labeled calmodulin have been established. These methods detect calmodulin-binding proteins on a gel or membrane after the proteins are separated by SDS-PAGE. Commonly used probes to detect calmodulin-binding proteins are 125 I-labeled calmodulin (14) and biotinylated calmodulin $(1,2)$. Another more recently developed probe is the ${ }^{32} \mathrm{P}$-labeled glutathione S-transferase (GST) calmodulin fusion protein (3). The disadvantages of radiolabeled probes are that they are more hazardous to work with than nonradiolabeled probes, require the purchase of protective shielding equipment, and require resynthesis and purification every few months. In addition, the 125I-labeled calmodulin method often does not produce clearly defined bands on a blot. The biotinylated calmodulin produces clearly defined bands on a blot; however, because the overlay uses avidin, the binding of avidin to endogenous biotincontaining proteins is likely to occur. This nonspecific binding makes the determination of calmodulin-binding proteins more difficult. Furthermore, detection with biotinylated calmodulin is often variable because of variations in the levels of biotinylation of calmodulin. Therefore, our goal was to devise a reliable nonradioactive detection method that eliminated usage of the avidin-biotin system. This paper describes the generation of an S-tag ${ }^{\mathrm{TM}}-\mathrm{la}-$ beled calmodulin fusion protein, detection using S-protein ${ }^{\mathrm{TM}}$ (Novagen, Madison, WI, USA) overlay assay, and the comparison of this method with the biotinylated calmodulin overlay assay for the evaluation of calmodulin-binding proteins in rat colon tissue and the HT-29 colon cancer cell line.

\section{MATERIALS AND METHODS}

\section{Generation of the Fusion Protein}

Plasmid pCaMpI, a generous gift obtained from Dr. Anthony Means (Duke University Medical Center, Durham, NC, USA), contains chicken calmodulin cDNA, which encodes for the same amino acid sequence as human and rat calmodulin $\left(\mathrm{GenBank}^{\circledR}\right.$, National Center for Biotechnology Information) (7). The plasmid was cut with restriction enzymes ( $N c o$ I and $X b a I)$ to create two fragments of the original plasmid. The fragments were separated by agarose gel electrophoresis and the chicken calmodulin cDNA fragment was extracted from the gel and recovered using phenol and ethanol precipitation. The calmodulin cDNA fragment was amplified by PCR using the primers 5'-GACGACGACAAGATGGCTGATCAACTGACAGAA- ${ }^{\prime}$ and 5'-GAGGAGAAGCCCGGTTCACTTCGCTGTCATCATCT- $3^{\prime}$ to create an insert for the pET-32 Ek/LIC vector (Novagen). The PCR product was purified by Wizard ${ }^{\circledR}$ PCR Preps DNA Purification System (Promega, Madison, WI, USA) and cloned/transformed according to the pET-32 Ek/LIC Vector Kit (Novagen). The purified PCR product was treated with T4 DNA polymerase, annealed to the pET-32 Ek/LIC vector, and transformed into NovaBlue Singles competent cells (Novagen). 
Insertion of the calmodulin cDNA and transformation of NovaBlue Singles competent cells was verified by a PCR colony screen using standard protocols (12). The plasmid was purified from the NovaBlue cells with the Wizard Miniprep DNA Purification Kit (Promega) and transformed into BL21(DE3) cells. The transformed BL21(DE3) cells were grown in $1 \mathrm{~L}$ of LB broth containing $100 \mu \mathrm{g} / \mathrm{mL}$ ampicillin until the broth was measured 0.6 at $\mathrm{A}_{600}$. The cells were induced by 1 $\mathrm{mM}$ isopropyl- $\beta$-D-thiogalactopyranoside (IPTG) for $2 \mathrm{~h}$ to produce a fusion protein containing thioredoxin, a histidine-tag (His-tag) and an S-tag-labeled calmodulin (Figure 1). The induced cells were disrupted using a French pressure cell, and the fusion protein was separated from the rest of the cellular contents using a nickel column (Novagen). Presence of the fusion protein at $30 \mathrm{kDa}$ was verified by separation with SDS-PAGE and visualized by staining with Coomassie ${ }^{\circledR}$ Brilliant Blue R250. The fusion protein was cleaved with $1 \mathrm{U}$ thrombin (Novagen) $/ \mathrm{mg}$ fusion protein to produce a thioredoxin-His tag fragment and an Stag-labeled calmodulin. The thrombin cleavage was confirmed by SDS-PAGE and visualized by staining with Coo- massie Brilliant Blue R250. To ensure that thrombin did not affect other proteins in subsequent overlay assays, it was irreversibly inactivated by $1 \mathrm{mM}$ phenylmethylsulfonyl fluoride (PMSF), as confirmed by incubating a cleavage test protein (Novagen) with thrombin in the presence of $1 \mathrm{mM}$ PMSF. Further purification of S-tag calmodulin was accomplished by nickel column, which removed the thioredoxin His-tag portion of the fusion protein. Purity was confirmed by SDSPAGE, showing the presence of S-tag calmodulin at $17 \mathrm{kDa}$ and the absence of thioredoxin His-tag (11 kDa). No other proteins were detected in the sample using Coomassie Brilliant Blue R250 staining (data not shown). The resulting S-tag calmodulin was employed in an overlay assay that utilized the binding of the S-tag portion (a 9 amino acid sequence) of the protein to a $S$ protein (a 105 amino acid sequence) horseradish peroxidase (HRP) conjugate (Novagen).

\section{Calmodulin Assay}

To evaluate the S-tag calmodulin under native conditions, purified calmodulin (Sigma, St. Louis, MO, USA), S-tag calmodulin, and two lots of bio-

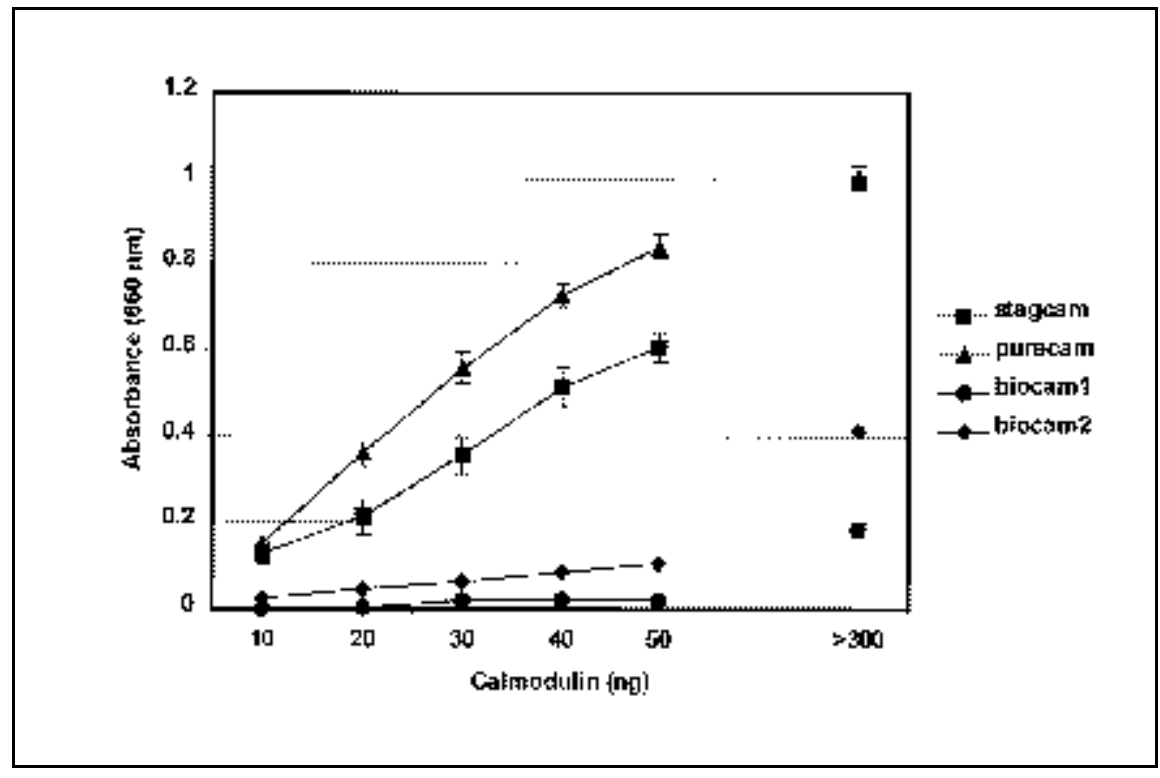

Figure 1. Comparison of purified calmodulin, biotinylated calmodulin, and S-tag calmodulin in the phosphodiesterase assay. Maximal $\mathrm{Ca}^{2+}$-dependent activation of phosphodiesterase was achieved with excess S-tag calmodulin but not biotinylated calmodulin. Activation of phosphodiesterase by biotinylated calmodulin was significantly lower than activation by S-tag calmodulin or purified unlabeled calmodulin at concentrations of $10-50 \mathrm{ng}$ calmodulin ( $P<0.05$ by two-way ANOVA). tinylated calmodulin (lot no. B19657 and lot no. B24095; Calbiochem-Novabiochem, San Diego, CA, USA) were compared using the phosphodiesterase assay (13). This enzyme assay measures the ability of calmodulin to activate the calmodulin-binding protein, cyclic nucleotide phosphodiesterase. Calmodulin-stimulated activation of phosphodiesterase activity was assessed in the presence and absence of $\mathrm{Ca}^{2+}$ (in the presence of EGTA). The difference, representing the $\mathrm{Ca}^{2+}$-dependent activation of phosphodiesterase, is reported.

\section{Overlay Assay}

To measure its ability to detect calmodulin-binding proteins under denatured conditions, the S-tag calmodulin was compared to biotinylated calmodulin in an overlay assay. Samples of the HT-29 colon cancer cell line (ATCC, Manassas, VA, USA) and normal rat colon tissue were evaluated. HT-29 cells were maintained in McCoys 5A modifed media (Biowhittaker, Walkerville, MD, USA) at $37^{\circ} \mathrm{C}, 100 \%$ humidity, and $5 \% \mathrm{CO}_{2}$. At $90 \%$ confluency, media were removed from the cell monolayer by two washes of versene (Life Technologies, Rockville, MD, USA). Ripa lysing buffer containing $150 \mathrm{mM} \mathrm{NaCl}, 0.5 \%$ DOC, $0.1 \%$ SDS, $50 \mathrm{mM}$ Tris, $\mathrm{pH} 8.0,0.2 \mathrm{mM}$ PMSF, $1 \mathrm{mM}$ benzamidine, and 1 $\mu \mathrm{g} / \mathrm{mL}$ leupeptin was added to the flask at $0.5 \mathrm{~mL}$ Ripa buffer $/ 1 \times 10^{7}$ cells. The cells were incubated in a rocker on ice for $30 \mathrm{~min}$, and the resulting lysate was transferred to a $1.5-\mathrm{mL}$ microcentrifuge tube. The lysate was centrifuged at $12000 \times g$ at $4^{\circ} \mathrm{C}$ for $30 \mathrm{~min}$. The supernate was removed from the pellet and boiled in sample buffer containing 50 $\mathrm{mM}$ Tris-HCl, pH 6.8, 2.5\% SDS, 0.12 M sucrose, 0.5 M 2-mercaptoethanol, and $0.01 \%$ bromophenol blue.

Normal rat colon tissue was collected from a male Sprague Dawley rat killed by $\mathrm{CO}_{2}$ asphyxiation. All subsequent procedures in preparing the colon tissue sample were carried out on ice or at $4^{\circ} \mathrm{C}$. The colon was washed several times with PBS ( $\mathrm{pH} \mathrm{7.4)} \mathrm{to} \mathrm{remove} \mathrm{the} \mathrm{fecal}$ matter, the colon was cut open lengthwise, and the mucosa was scraped off and placed into a tube. The mucosa was 
suspended in homogenizing buffer containing $100 \mathrm{mM}$ Tris (pH 7.4), $1 \mathrm{mM}$ EGTA, $1 \mathrm{mM}$ EDTA, $10 \mathrm{mM}$ mercaptoethanol, $0.2 \mathrm{mM}$ PMSF, $1 \mathrm{mM}$ benzamidine, and $1 \mu \mathrm{g} / \mathrm{mL}$ leupeptin. The tissue was homogenized with a homogenizing probe (PowerGen ${ }^{\mathrm{TM}}$ 125; Fisher Scientific, Pittsburgh, PA, USA) at maximum speed in $3 \times 10 \mathrm{~s}$ intervals. The sample was filtered through glass wool to remove any fatty tissue, placed in a microtube, and centrifuged at $12000 \times g$ for $30 \mathrm{~min}$. The resulting supernate was boiled in the same sample buffer used for the HT-29 cells.

Protein concentrations of the supernates were determined by the Bradford method (8) using a standard curve generated with bovine serum albumin. Samples of HT-29 cells and normal rat colon tissue $(25 \mu \mathrm{g}$ protein) were separated by SDS-PAGE and transferred onto nitrocellulose membranes. An overlay procedure described previously (5) was followed for biotinylated calmodulin (lot no. B24095; Calbio-
chem-Novabiochem) with an exception of using $20 \mathrm{mM}$ imidazole in the wash and incubation buffers. Additionally, an avidin $(0.01 \%)$ and biotin $(0.01 \%)$ block was used to reduce detection of endogenous biotinylated proteins as previously described (5).

An overlay procedure similar to one used for I ${ }^{125}$-labeled calmodulin overlay (14) was used for the S-tag-labeled calmodulin. The membranes were incubated in $0.1 \mathrm{M}$ imidazole for $10 \mathrm{~min}$, followed a 40-min incubation in a blocking solution containing $20 \mathrm{mM}$ imidazole, $0.2 \mathrm{M} \mathrm{KCl}, 1 \% \mathrm{BSA}$, and either $1 \mathrm{mM}$ calcium chloride or $1 \mathrm{mM}$ EGTA. The membranes were rinsed twice in a wash buffer containing 20 $\mathrm{mM}$ imidazole, $0.2 \mathrm{M} \mathrm{KCl}, 0.1 \% \mathrm{BSA}$ with either $1 \mathrm{mM}$ calcium chloride or 1 mM EGTA. The membranes were incubated for $2 \mathrm{~h}$ in the wash buffer solution containing $200 \mathrm{ng}$ S-tag calmodulin/ $\mathrm{mL}$ wash buffer $\left(2 \mathrm{~mL}\right.$ wash buffer $/ \mathrm{cm}^{2}$ membrane for each wash). The S-tag calmodulin incubation was followed by $3 \times 7$ min washes in wash buffer. The membranes were incubated for $30 \mathrm{~min}$ in the wash buffer containing $\mathrm{S}$-protein HRP at a dilution of 1:5000. The membranes were washed with two quick rinses followed by $3 \times 7$ min washes in the wash buffer. Calmodulin-binding proteins were detected by using the ECL $^{\circledR}$ detection kit on ECL Hyperfilm ${ }^{\mathrm{TM}}$ according to the manufacturer's procedures (Amersham Pharmacia Biotech, Piscataway, NJ, USA). The positive and negative controls for a specific overlay were conducted on the same day and were exposed on one film, thereby ensuring exactly the same exposure time. Images were scanned using a Bio-Rad ${ }^{\circledR}$ Model GS-700 Imaging Densitometer (Bio-Rad Laboratories, Hercules, CA, USA).

\section{RESULTS AND DISCUSSION}

The results from the calmodulin-dependent cyclic nucleotide phosphodiesterase assay indicate that maximal activation of phosphodiesterase, in the presence of $\mathrm{Ca}^{2+}$, was achieved with excess (>300 ng) S-tag calmodulin (stagcam) and excess purified calmodulin (purecam) but not with excess biotinylated calmodulin from either lot (biocam1 and biocam2) (Figure 1). Activation of calmodulin-dependent phosphodiesterase by S-tag calmodulin was significantly higher than by either lot of biotinylated calmodulin at all concentrations $(P<0.05$ by two-way ANOVA). Therefore, addition of the $\mathrm{S}$ tag to calmodulin had less effect on the ability of calmodulin to activate calmodulin-dependent phosphodiesterase than did biotinylation of calmodulin. At concentrations of 10-50 ng calmodulin, the activation of phosphodiesterase activity by purified calmodulin is significantly higher than by S-tag calmodulin and biotinylated calmodulin, indicating that the addition of the S-tag to calmodulin may also affect the interaction of calmodulin with calmodulin-binding proteins.

Figure 1 also illustrates that maximal activation of phosphodiesterase differed between the two lots of biotinylated calmodulin obtained from the same supplier. The location and stoichiometry of biotinylation of calmodulin may differ from lot to lot, and from supplier to supplier. A study conducted by Mann and Vanaman (4) demonstrated that calmodulin, biotinylated on lysine-94, activated phosphodiesterase similarly to purified calmodulin with maximal activation at 50-60 ng. For calmodulin, biotinylated on lysine-75, $500 \mathrm{ng}$ protein were required for maximal activation (4). These results suggest that the interaction between calmodulin-dependent phosphodiesterase, and potentially other calmodulin-dependent proteins and calmodulin, is dependent on the calmodulin labeling. Although activation of phoshodiesterase may not correlate with binding with calmodulin-binding proteins on a blot, these results suggest that, lot to lot and supplier to supplier, differences in biotinylation of calmodulin may affect the detection of calmodulin-binding proteins by biotinylated calmodulin in overlay assays. We observed that the two lots tested for phosphodiesterase activation also differed in detection of calmodulin-binding proteins using the overlay assay (data not shown). Information on the location and stoichiometry of biotinylation is often not available from the supplier, making it difficult to predict the effectiveness of the biotinylated calmodulin in an over- 


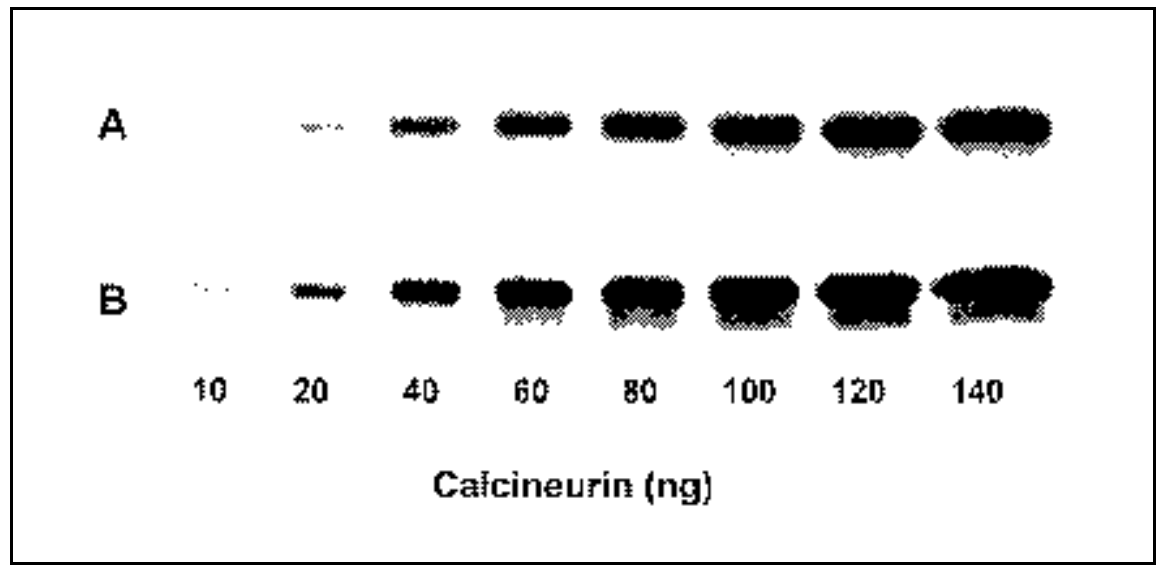

Figure 2. Quantitative detection of calcineurin using biotinylated calmodulin and S-tag calmodulin overlay. The sensitivity of detection of calcineurin was higher in the S-tag calmodulin overlay (blot B) compared to the biotinylated calmodulin (blot A) overlay.

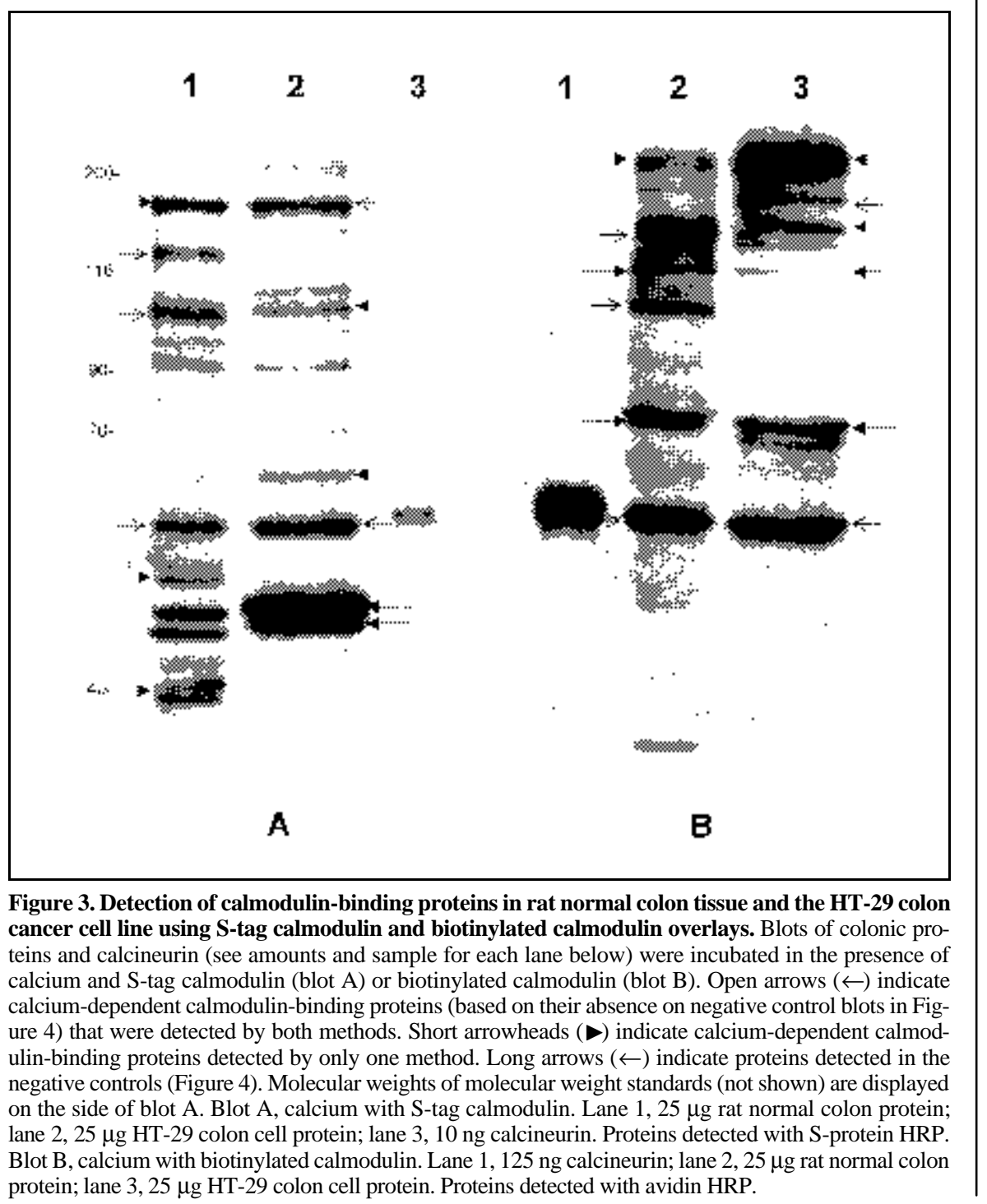


lay assay. The advantage of the S-tag calmodulin and the 32P-labeled GST calmodulin fusion protein (3) is that the location and stoichiometry of the label on the calmodulin remains the same from lot to lot.

A comparison between biotinylated calmodulin and S-tag calmodulin overlays demonstrated that S-tag calmodulin is more sensitive than biotinylated calmodulin in detecting calcineurin, a known calmodulin-binding protein (Figure 2). The increased sensitivity is more pronounced at lower concentrations, especially in the range of 10-80 ng calcineurin. These data suggest that the S-tag calmodulin binds to calcineurin more effectively than biotinylated calmodulin, which is in agreement with results from the calmodulin-dependent phosphodiesterase assay.

Calmodulin-binding proteins were detected in rat normal colon tissue and the HT-29 colon cancer cell line using the biotinylated calmodulin and S-tag calmodulin overlays. A comparison of the positive controls is shown in Figure 3 . Both overlays demonstrate that several calcium-dependent calmodulinbinding proteins are present in colon tissue and cells. In the rat normal colon, both methods detected proteins at 130 , 105-110, and $60 \mathrm{kDa}$ (long arrows). Additional proteins detected only in the S-tag calmodulin overlay (arrowheads; Figure 3, panel A) included proteins at 160,50 , and $40 \mathrm{kDa}$. An additional band was found in the biotinylated calmodulin overlay assay at greater than $200 \mathrm{kDa}$ (arrowhead; Figure 3, panel B). The analysis of HT-29 cells showed that molecular weight proteins at 160 and $60 \mathrm{kDa}$ were detected with both assays (long arrows). An additional band at $105-110 \mathrm{kDa}$ was detected only in the S-tag calmodulin overlay of HT-29 cells. Additional bands detected by the biotinylated calmodulin overlay

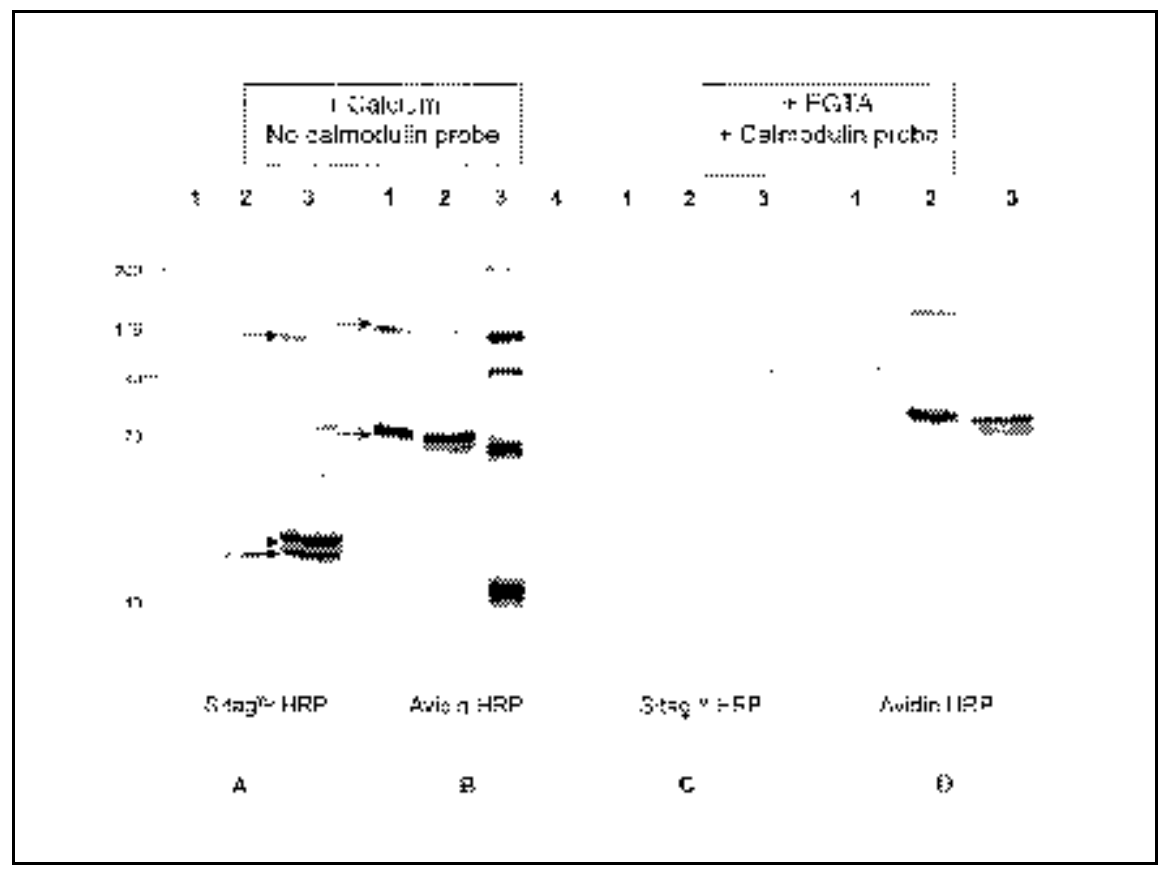

Figure 4. Negative controls of the S-tag and biotinylated calmodulin overlays. Blots of colonic proteins and calcineurin (see amounts and sample for each lane below) were incubated in the presence of calcium without S-tag calmodulin (blot A) or without biotinylated calmodulin (blot B). Parallel blots were incubated in the presence of EGTA with S-tag calmodulin (blot C) or biotinylated calmodulin (blot D). Molecular weights of molecular weight standards (not shown) are displayed on the side of blot A. Blot A, calcium without S-tag calmodulin. Lane 1,125 ng calcineurin; lane 2, $25 \mu \mathrm{g}$ rat normal colon protein; lane 3, $25 \mu \mathrm{g}$ HT-29 colon cell protein. Proteins detected using S-protein HRP. Blot B, calcium without biotinylated calmodulin. Lane 1, $25 \mu \mathrm{g}$ rat normal colon protein; lane 2, $25 \mu \mathrm{g}$ HT-29 colon cell protein; lane 3, biotinylated molecular weight standard; lane 4, $125 \mathrm{ng}$ calcineurin. Proteins detected using avidin HRP. Blot C, EGTA plus S-tag calmodulin. Lane 1, $125 \mathrm{ng}$ calcineurin; lane 2, $25 \mu \mathrm{g}$ rat normal colon protein; lane 3, $25 \mu \mathrm{g}$ HT-29 colon cell protein. Proteins detected using S-protein HRP. Blot D, EGTA plus biotinylated calmodulin. Lane 1, $125 \mathrm{ng}$ calcineurin; lane 2, $25 \mu \mathrm{g}$ rat normal colon protein; lane $3,25 \mu \mathrm{g}$ HT-29 colon cell protein. Proteins detected using avidin HRP.

assay of HT-29 cells were proteins found at 145 and greater than $200 \mathrm{kDa}$ (arrowheads; Figure 3, panel B).

These findings are similar to previous reports of calmodulin-binding proteins in intestinal tissue. Adult human colon brush border membrane has been shown to contain calmodulin-binding proteins at $105-110,145,160$, and $240 \mathrm{kDa}$ using the 125 I calmodulin overlay (10). The proteins were identified as calmodulinbinding proteins called fodrin $(240 \mathrm{kDa})$, fodrin proteolytic fragment $(160 \mathrm{kDa})$, caldesmon (145 kDa), and brush border myosin I (110 kDa) (10). These calmodulin-binding proteins were also identified in rat jejunal epithelial cells (9).

The negative controls of both methods demonstrate that each case, the reporter conjugate (S-protein HRP or avidin HRP) binds to proteins in the absence of calmodulin (Figure 4). A 67$\mathrm{kDa}$ protein doublet appearing in all of the biotinylated calmodulin overlay negative control blots (Figure 4, panels $\mathrm{B}$ and D) has previously been reported to be the major calmodulin-binding protein in normal and tumorous colon tissue using the biotinylated calmodulin overlay assay (5). The absence of the $67-\mathrm{kDa}$ protein in the EGTA control from the study conducted by McGarrity et al. (5) may have been due to EGTA inhibition of the alkaline phosphatase conjugate (15). In our laboratory, the presence of $1 \mathrm{mM}$ EGTA in the buffer containing avidin-alkaline phosphatase completely inhibited detection of the 67-kDa doublet, whereas inclusion of EGTA in all incubation buffers up to but not including the final detection step did not inhibit detection (data not shown). This illustrates the potential misinterpretation of the EGTA negative control, if an alkaline phosphatase conjugate is used for detection. The results from the positive control of the $S$ tag calmodulin assay (Figure 3, panel A) also indicate that there are no calmodulin-binding proteins at $67 \mathrm{kDa}$ in rat colon tissue or in HT-29 cells.

Interestingly, proteins detected by $\mathrm{S}$-protein HRP in the calcium-without S-tag calmodulin negative control (Figure 4, panel A) were not detected in the presence of EGTA and S-protein HRP (Figure 4, panel C). HRP, a calciumcontaining metalloprotein, has been shown to become less thermally stable 
when guanidine hydrochloride and EDTA remove calcium (11). Although it appeared that inhibition of the S-protein HRP conjugate was occurring in the S-tag calmodulin negative control overlay, EGTA did not inhibit avidin HRP in the biotinylated calmodulin negative control overlay, as bands are present (Figure 4, panel D). Consequently, this illustrates the importance of conducting both negative control blots. If we had not used the negative control of calcium-without S-tag calmodulin in our assays, we would have incorrectly interpreted that all the bands detected on positive control of the S-tag calmodulin overlay were calciumdependent calmodulin-binding proteins.

Detection of calmodulin-binding proteins in tissue and cell samples is complex, and each method has limitations. The limitations of the avidin-biotin system used by the biotinylated calmodulin overlay have been described previously (2), including binding to endogenous biotin-containing proteins and binding to other biotin molecules present in the blocking agent. Limitations of the S-tag calmodulin overlay are also apparent from the calcium-containing negative controls; however, the proteins binding S-protein HRP are not known. The S-protein portion of the S-protein HRP conjugate derived from pancreatic ribonuclease is designed to specifically bind only to an S-tag amino acid sequence. Therefore, we did not expect bands on the negative controls. Previous assays (data not shown) with HRP substrates have indicated that none of the proteins in our samples contain endogenous HRP activity. Use of the negative control of calcium-without S-tag calmodulin allowed for clear identification of calcium-dependent calmodulin-binding proteins on the positive blot.

We conclude that the S-tag calmodulin overlay is a useful method because it eliminates the possibility of binding to endogenous biotin-containing proteins. It is a rapid, nonradioactive assay that utilizes a stable tag always bound to the $\mathrm{N}$ terminus of calmodulin. This method, when used with the appropriate negative controls, provides useful information about the presence of calmodulin-binding proteins in tissue and cell samples.

\section{ACKNOWLEDGMENTS}

We thank Dr. Anthony Means (Duke University Medical Center, Durham, NC, USA) for the pCaMp1 plasmid and for helpful suggestions during this study. The excellent technical assistance of K. Hendrix is gratefully acknowledged. This work was supported by a grant from the United Dairymen of Idaho to B.A.M. and by the University of Idaho Agricultural Experiment Station.

\section{REFERENCES}

1.Billingsley, M.L., K.R. Pennypacker, C.G. Hoover, D.J. Brigati, and R.L. Kincaid. 1985. A rapid and sensitive method for detection and quantification of calcineurin and calmodulin-binding proteins using biotinylated calmodulin. Proc. Natl. Acad. Sci. USA 82:7585-7589.

2.Billingsley, M.L., J.W. Polli, K.R. Pennypacker, and R.L. Kincaid. 1990. Identification of calmodulin-binding proteins. Methods Enzymol. 184:451-467.

3.Fischer, R., Y. Wei, and M. Berchtold. 1996. Detection of calmodulin-binding proteins us- ing a 32P-labeled GST-calmodulin fusion protein and a novel renaturation protocol. BioTechniques 21:292-296.

4.Mann, D. and T.C. Vanaman. 1987. Specific chemical modification as a probe of calmodulin function, p. 417-433. In A.R. Means and P.M. Conn (Eds.), Methods in Enzymology, vol. 139. Academic Press, Orlando, FL.

5.McGarrity, T.J., L.P. Peiffer, and M.L. Billingsley. 1991. Interspecies comparison of calmodulin binding proteins throughout the gastrointestinal tract:comparison with human colon adenomas and adenocarcinomas. Gut 32:1121-1126.

6.Niki, I., H. Yokokura, S. Toshiki, M. Kato, and H. Hiroyoshi. 1996. $\mathrm{Ca}^{2+}$ signaling and intracellular $\mathrm{Ca}^{2+}$ binding proteins. J. Biochem. 120:685-698.

7.Putkey, J.A., G.R. Slaughter, and A.R. Means. 1985. Bacterial expression and characterization of proteins derived from the chicken calmodulin cDNA and a calmodulin processed gene. J. Biol. Chem. 260:4704-4712.

8.Rasmussen, C.D. and A.R. Means. 1989. Calmodulin, cell growth and gene expression. Trends Neurosci. 12:433-438.

9.Rochette-Egly, C. and K. Haffen. 1987. Developmental pattern of calmodulin-binding proteins in rat jejunal epithelial cells. Differentiation 35:219-227.

10.Rochette-Egly, C., M. Kedinger, and K. Haffen. 1988. Modulation of HT-29 human colonic cancer cell differentiation with calmidazolium and 12-O-tetradecanoylphorbol-13acetate. Cancer Res. 48:6173-6182.

11.Ryan, O., M.R. Smyth, and C.O. Fagain. 1994. Horseradish peroxidase: the analyst's friend. Essays Biochem. 28:129-146.

12.Sambrook, J., E.F. Fritsch, and T. Maniatis. 1989. Molecular Cloning: A Laboratory Manual, 2nd ed., vol. 1. CSH Laboratory Press, Cold Spring Harbor, NY.

13.Sharma, R.K. and J.H. Wang. 1979. Preparation and assay of the $\mathrm{Ca}^{2+}$-dependent modulator protein. Adv. Cyclic Nucleotide Res. 10:187-198.

14.Slaughter, G.R. and A.R. Means. 1987. Use of the 125 I-labeled protein gel overlay technique to study calmodulin-binding proteins, $\mathrm{p}$. 433-44. In A.R. Means and P.M. Conn (Eds.), Methods in Enzymology, vol. 139. Academic Press, Orlando, FL.

15.Szajn, H. and H. Csopak. 1977. Metal ion-induced conformational changes in Escherichia coli alkaline phosphatase. Biochim. Biophys. Acta 480:143-153.

16.Wang, J.H., C.J. Pallen, R.K. Sharma, A.M. Adachi, and K. Adachi. 1985. The calmodulin regulatory system. Curr. Top. Cell. Regul. 27:419-436.

Received 24 July 2000; accepted 22 November 2000.

Address correspondence to:

Dr. Bernadene A. Magnuson

Department of Nutrition and Food Science 3304 Marie Mount Hall

University of Maryland

College Park, MD 20742-7521, USA

e-mail:bm150@umail.umd.edu 